\title{
Bergsoniana
}

1 | 2021

Reassessing Bergson

\section{What Bergson Should Have Said to Einstein}

\section{Steven Savitt}

\section{OpenEdition}

\section{Journals}

Electronic version

URL: https://journals.openedition.org/bergsoniana/333

DOI: 10.4000/bergsoniana.333

ISSN: $2800-874 X$

\section{Publisher}

Société des amis de Bergson

\section{Electronic reference}

Steven Savitt, "What Bergson Should Have Said to Einstein", Bergsoniana [Online], 1 | 2021, Online since 01 July 2021, connection on 08 November 2021. URL: http://journals.openedition.org/bergsoniana/ 333 ; DOI: https://doi.org/10.4000/bergsoniana.333

$\mathrm{BY}$

Les contenus de la revue sont mis à disposition selon les termes de la Licence Creative Commons Attribution 4.0 International. 


\title{
WHAT BERGSON SHOULD HAVE SAID TO EINSTEIN ${ }^{1}$
}

\author{
Steven SAVITT
}

Let me begin by repeating (changing only the name) a paragraph from a recent paper by David Chalmers:

I should say that I am not a historian or a serious scholar of Bergson. These are merely some speculative remarks not well-grounded in scholarly attention to Bergson's texts. But I think the speculative question is interesting. I'm going to sketch one speculative answer. I'm going to be interested to hear from people who know much more about Bergson than I do about whether this speculation has any remote plausibility. If the historical speculation has none, as may well be possible, I think there is still a very interesting philosophical project in the neighbourhood which is itself worthy of attention (Chalmers 2018).

My speculative remarks concern the famous debate between Henri Bergson and Albert Einstein that took place in Paris on 6 April 1922. This encounter has recently received a book-length treatment (Canales 2015), but little of the substance of the debate was actually reported in it. Einstein and Bergson disagreed, unsurprisingly, as to whether time is better understood through scientific or philosophical examination. ${ }^{2}$ But in

1. This paper, aside from minor editorial changes, was delivered at the Reasssessing Bergson conference held in Cambridge, England on 11-12 September 2019. I am grateful to the co-organisers of the conference (Theo Borgvin-Weiss, Florian Fischer, Matyáš Moravec, Sam Sokolsky-Tifft, and Zoe Walker) for inviting me to this meeting. While my paper was in press, it has come to my attention (4 June 2020) that a second paper arguing that Bergson should have embraced local passage in relativistic spacetimes (Kügler, 2020) was published online by Synthese (28 May 2020). It was received by that journal 11 December 2019.

2. Indeed, as we shall see, Canales (2015) cites this debate as one of the sources of the increasing gulf between scientific and humanistic treatments of time in the $20^{\text {th }}$ century. 
regard specifically to Bergson's views concerning time in the special theory of relativity, we have the evidence of a book he wrote on that topic at the time of the debate, Duration and Simultaneity. ${ }^{3}$ My remarks in this paper primarily concern claims of Bergson in that book, claims that deal specifically with time in the Special Theory of Relativity (STR), and I will leave it to others, should they wish, to tease out their implications for some of Bergson's more general theses concerning time.

STR is well-known for showing that certain quantities or relations (length, mass, simultaneity) that were regarded as frame-invariant or absolute in pre-relativistic physics are actually frame-dependent or relative. One standard and striking illustration of these novel and unintuitive ideas is the so-called "twin paradox." ${ }^{4}$ One way of presenting the "paradox" is to imagine a pair of identical twins. One travels to a distant galaxy on a rocket ship at very high speed and then returns to earth at the same high speed. The other remains on earth. STR implies that the travelling twin on their return will have aged less than the stay-at-home twin.

Bergson did not accept this conclusion. In fact, he argued that (1) The clock paradox is false. The sort of behavior described in the clock paradox will not in fact occur using clocks in our world. (2) The clock paradox results from a misunderstanding of STR. Therefore, one can deny that the behavior described in the clock paradox would actually occur while accepting all of STR (that is, all the valid mathematical/physical core of STR) itself.

I think that any fair-minded reader of Duration and Simultaneity will agree that Bergson argued for (1) and (2) above. Let me give just one bit of textual evidence (from the third Appendix to the second edition) that supports both claims.

In short, there is nothing to change in the mathematical expression of the theory of relativity. But physics would render a service to philosophy by giving up certain ways of speaking which lead the philosopher into error, and which risk fooling the physicist himself regarding the metaphysical implications of his views. For

3. Duration and Simultaneity was first published in French in 1922 as Durée et Simultanéité. A second edition was published in 1923 with three important appendices added. The English translation that I cite throughout was published in 1965.

4. I prefer to refer to it by the more generic term the clock paradox. Of course, it is not a paradox at all; it is just one of the many counter-intuitive implications of STR. For an illuminating, at-the-time-comprehensive discussion of failed responses to the clock paradox see Marder (1971). For a sophisticated modern philosophical account of the "paradox" see (Arthur, 2019, chapters 5 and 6). 
example, we are told above that "if two identical, synchronised clocks are at the same spot in the system of reference, if we shift one very rapidly and then bring it back again next to the other at the end of time $t$ (the time of the system), it will lag behind the other [...]." In reality, we should say that the moving clock exhibits this slowing at the precise instant at which it touches, still moving, the motionless system and is about to re-enter it. But immediately upon re-entering, it points to the same time as the other [...] (Bergson 1965,185).

Unfortunately, claims (1) and (2) are incorrect. In 1971 an experiment was done that directly tested the clock "paradox." It was reported in a two-part paper. I will simply quote the abstracts to the two parts:

During October 1971, four cesium beam atomic clocks were flown on regularly scheduled commercial jet flights around the world twice, once eastward and once westward, to test Einstein's theory of relativity with macroscopic clocks. From the actual flight paths of each trip, the theory predicts that the flying clocks, compared with reference clocks at the U.S. Naval Observatory, should have lost $40 \pm 23$ nanoseconds during the eastward trip, and should have gained $275 \pm$ 21 nanoseconds during the westward trip. The observed time differences are presented in the report that follows this one (Hafele, J. C. and R. Keating, 1972a).

Four caesium beam clocks flown around the world on commercial jet flights during October 1971, once eastward and once westward, recorded directionally dependent time differences which are in good agreement with predictions of conventional relativity theory. Relative to the atomic time scale of the U.S. Naval Observatory, the flying clocks lost $59 \pm 10$ nanoseconds during the eastward trip and gained $273 \pm 7$ nanoseconds during the westward trip, where the errors are the corresponding standard deviations. These results provide an unambiguous empirical resolution of the famous clock "paradox" with macroscopic clocks (Hafele, J. C. and R. Keating, 1972b).

So, thesis (1) above is false. As for (2), it is important to see not just that it is false, but also how central it is to STR that it is false. To that end, choose an arbitrary point $\mathrm{p}$ in the spacetime of the special theory of relativity, Minkowski spacetime (choosing a point in spacetime means specifying four coordinates - three spatial and one temporal). And then choose a second point $\mathrm{q}$ such that a material clock can travel from $\mathrm{p}$ to $\mathrm{q}$ without ever exceeding the speed of light. These two points are said to be timelike separated, with q future to $\mathrm{p}$. The path from $\mathrm{p}$ to $\mathrm{q}$ in spacetime is called a future-directed timelike curve.

The Hafele and Keating experiment shows empirically that for two clocks starting at a given point $p$ and meeting later at a given point $q$ the same time will in general not have elapsed for them along distinct future-directed timelike curves. This result is known as the path dependence of (proper) time. 
Suppose that (proper) time were not path dependent in this way. That is, suppose that the elapsed time indicated by the two clocks travelling along different timelike curves from $p$ to $q$ were always the same. Then if one assigned some time to $\mathrm{p}$ (let us say 0 ) and if it took both clocks the same time $t$ to reach $q$, one could assign that time $t$ to $q$ unambiguously. But since $q$ was chosen arbitrarily, one could evidently assign a definite time unambiguously to every point in spacetime. That would in turn enable one to collect together into sets all points in the spacetime that are assigned a given time, all points or events that are simultaneous. That is, one could divide or slice or foliate the whole of the spacetime unambiguously or uniquely into sets of simultaneous points (simultaneity slices).

A spacetime with this structure is called Galilean spacetime. ${ }^{5}$ It is the spacetime perhaps best adapted to be the setting of Newton's mechanics, but it has too much structure (the unique same-time slices or surfaces) to be Minkowski spacetime, the spacetime of STR. So, denying the path dependence of (proper) time is flatly inconsistent with STR. ${ }^{6}$ The pathdependence of time is, then, central to STR. The clock paradox is merely one specific manifestation of the path-dependence of time, so the clock paradox is central to STR. To deny its centrality, as Bergson did, is a mistake. According to Canales, Bergson paid dearly for this mistake. He enjoyed rock-star celebrity in 1922 but died in obscurity.

By the time Bergson died on January 3, 1941, the event was particularly shocking because the world had already fallen into the habit of thinking of him as dead. His debate with Einstein precipitated the vertiginous downward fall (Canales 2015, 31).

What I wish to say here, tentatively, is that it need not have been so. Bergson did not play the cards that were in his philosophical hand as well as he could have in the debate with Einstein (and in Duration and Simultaneity). It might well have been better for him personally and for the course of philosophy in the $20^{\text {th }}$ century if he had. I will now try to make this case, but I would like to lay it out in a slightly round-about manner.

5. See Chapter 3 of Geroch (1978). The reader might find Figures 34 and 35 and the surrounding discussion in that book helpful. In general, the book provides a very helpful non-technical introduction to the notion of spacetime structure.

6. Ćapek (1971) claims that "Bergson was right as long as we remain within the framework of the special theory of relativity" (p. 246). The common mistake that the general theory of relativity is required to remove the apparent paradoxical nature of the clock "paradox" is effectively dealt with in the book by Marder referred to above. 
First, I think that any fair-minded reader of Duration and Simultaneity would have to conclude that Bergson made a serious and sustained effort to understand STR. The theory was accepted by the community of theoretical or mathematical physicists surprising rapidly, but it was nevertheless a complex and counter-intuitive theory that still has the power to unsettle anyone who studies it. In the century since its advent, its central ideas have been clearly distinguished and the arguments for or derivations of the odd relativistic effects have been simplified and polished. ${ }^{7}$ It's much easier for us now to see what is essential to STR than it would have been for Bergson then.

It is not shocking, then, that he took an essential idea of STR for an optional philosophical gloss. He doubtless had salient reasons for (erroneously) convincing himself of this view; but I also think that he had sufficient respect for experiment to believe that, had it been possible to do an experiment like the Hafele and Keating experiment in, say, 1920, he would have accepted the result. Two real clocks make round-the-world trips in each direction. Neither of them is imaginary. I do not know what exactly led Bergson to reject the twin thought-experiment, to reject that idea (as I would like to put it now) that there could be real time along two trajectories in (Minkowski) spacetime between a pair of events, even though the times measured along the world lines were not the same. But I do think — or at least I would like to conjecture — that had he seen the evidence against (1) above, he would have changed his mind.

By the 1970s the state of knowledge had changed considerably from that of 1923. The question to ponder is not, I submit, whether Bergson would have changed his mind about the clock paradox, but how would he have changed it? I will hazard one conjecture, but I am aware that many others are possible. Consider this aphorism from Duration and Simultaneity: "[T]ime is succession" (Bergson 1965, 65). Let us ask ourselves what Bergson could say if he had been asked (or had asked himself): a succession of what? Most philosophers of time - and probably most non-philosophers as well - would after some thought suppose that time is a succession of sets or collections of simultaneous instantaneous events spanning the universe. (There might be some hesitation as to whether the events are instantaneous or have some small duration, but that choice makes no difference to my

7. For an elegant popular introduction to all the standard STR phenomena, see Mermin (1968). Mermin discusses the clock paradox on pages 187-194 in a version involving three inertial observers (and so no acceleration). It is remarkably instructive to calculate in detail the example from the perspective of each of the three clocks or "observers." 
story in this paper.) These sets of events occur one after another. That is, they occur successively. This succession is the unfolding or happening or history of the universe. ${ }^{8}$

This answer would not be available to Bergson. A global or universe-wide set of simultaneous events is what he would call - if I understand him correctly - a snapshot of the universe. The idea that time is the succession of such snapshots is precisely the cinematographic conception of time that he castigated in Creative Evolution. He might, of course, reconsider that old view of his, but a reconsideration in light of STR makes it less, rather than more, plausible. In STR, at any given spatio-temporal location there is no special (or "metaphysically privileged") snapshot. There are only an infinite number of equally non-special snapshots. This multiplicity does not provide an attractive foundation on which to build a metaphysics of time.

I believe there is a better choice for Bergson. Consider the two paths followed by two clocks connecting events $p$ and $q$. Each path is a set of events that occur successively. Each path could be the path of a space traveler. ${ }^{10}$ Instead of trying to confine real or lived time to just one such path, ${ }^{11}$ allow real or lived time, at least potentially, along each path. Embracing the twins rather than rejecting them is surely a step in the right direction, a recognition of what STR says and the weight of evidence in its favour.

But, of course, this step raises new questions. What of triplets? There is no reason to stop at two, it seems. Each of their three paths in spacetime would be sets of events that occur successively. To put this point another way, suppose there were three distinct time-like curves connecting points $p$ and $q$. Then there would be in general three distinct (proper) times along each such world line, each potentially equally "real" or lived or genuine. But once this line of thought is started, one should see that there is no natural finite end to it. There is no non-arbitrary upper bound on the number of time-like curves connecting $p$ and $q$ (or any other pair of points in spacetime) with associated proper times.

8. Bergson speaks of "the singleness of an impersonal time. Such is the hypothesis of common sense" (Bergson 1965, 47). He goes on to imply that Einstein supports this hypothesis.

9. A notion that is often invoked but rarely explained.

10. Allowing for the fact that, if the space traveler is human, some paths have accelerations that humans cannot survive.

11. "The real is that which is measured by a real physicist, and the imaginary, that which is represented in the mind of the real physicist as measured by imaginary physicists" (Bergson 1965, 79). 
Why not, then, trade the constricted or anemic conception of lived time that we find in Duration and Simultaneity (lived time on one time-like curve, ghostly time on the others) for a robust conception of genuine time flourishing equally on all time-like world lines? ${ }^{12}$ Of course, this need not presuppose or entail that all time-like worldlines are the paths in spacetime of conscious "observers" or clocks. It would entail or presuppose that all such worldlines are potentially the paths of such "observers" or clocks. On this view, Minkowski spacetime would teem with times. ${ }^{13}$

I have to say "times" because, as noted above, time is path dependent and there is a non-denumerable infinity of paths connecting any two timelike separated points like $p$ and $q$ in the discussion above. Although this plurality of times may seem philosophically puzzling, any account of time (or at least any that I am acquainted with) brings some philosophical puzzles in its train. But there is also a great philosophical advantage as well. This point of view is a necessary corrective to the mistake, often made by physicists as well as philosophers and historians, ${ }^{14}$ that the spacetime of STR is somehow "static" or a "block universe." Here, for instance, is the opinion of one eminent philosopher, Sir Karl Popper:

And a deterministic system such as the field theory of Einstein might even be described as a four-dimensional version of Parmenides' unchanging threedimensional universe. For in a sense no change occurs in Einstein's fourdimensional block-universe. Everything is there just as it is, in its four-dimensional locus; change becomes a kind of "apparent" change; it is "only" the observer who as it were glides along his world-line and becomes successively conscious of the different loci along this world-line; that is, of his spatio-temporal surroundings (Popper 1962, 80).

This sort of (confused, I suggest) idea is no doubt one that lies behind (or beneath) disputes about time that continue to this day. As Canales says,

As the [20th] century drew to a close, the "time of the universe" and "lived time" appeared as irreconcilable as science and philosophy in ways that exceeded the discussion that took place that day (Canales 2015, 348).

12. This picture is fleshed out and defended in Savitt (2009) and Savitt (2020). See also Rovelli (2019).

13. And Bergson did write "We believe that a philosophy in which duration is considered real and even active can quite readily admit Minkowski's and Einstein's space-time [...]" (Bergson 1965, 63).

14. Canales for instance, writes that "Einstein's theory [...] on its own [...] describes a universe where our sense of time passing by us was an illusion" (Canales 2015, 275). 
But this source of division (and confusion) could have been scotched by Bergson. Had Bergson accepted the result of the clock paradox, he could have correctly pointed out to Einstein that Minkowski spacetime, far from being a static or so-called "block universe," is chock-a-block (as it were) with temporal dynamism. ${ }^{15}$ For all I know, by the way, he could have been the first to point this out, thus gaining (from my point of view at least) a far more significant place in the history of philosophy and physics of time than he has today.

Students of Bergson may suspect that he could not have changed his views regarding STR in the way I have suggested without altering other, very fundamental views, as well. They may be right. My reflections above concern the behaviour of clocks - more specifically, the behaviour of ideal clocks on timelike world lines. For Bergson, such behaviour is only indirectly indicative of anything at all about time itself. Here's a typical remark in this vein:

It is therefore the simultaneity between two instants of two motions outside of us that enables us to measure time; but it is the simultaneity of these moments with moments pricked by them along our inner duration that makes this measurement one of time (Bergson 1965, 54).

The root idea here is, I believe, that time, real time, is accessible to our consciousness whereas the quantity measured by clocks is some sort of derivative quantity or secondary shadow of genuine duration. I think this view is deeply mistaken. We humans are clocks, albeit not particularly good clocks compared to today's best. We measure imperfectly what they measure far more exactly. We can experience what they measure in a way that, presumably, they cannot; but what we and they are responding to is one and the same, nonetheless. I cannot prove this, and it will not be possible to argue the point in any detail within the confines of this article. ${ }^{16}$ The best I can do in this short compass, I think, is to quote a perceptive statement of a view more like the one I favor by Ernst Cassirer:

For Newton it was certain that the absolute and mathematical time, which by its nature flowed uniformly, was the "true" time of which all empirically given temporal determination can offer us only a more or less imperfect copy; for Bergson, this "true" time of Newton is a conceptual fiction and abstraction, a

15. Capek $(1971,252)$ writes that Bergson "failed to see that the relativistic space-time, correctly interpreted, far from implying the elimination of becoming, reintroduces it into the physical world." Either Bergson failed to see this correct interpretation, or he thought that it had philosophical costs that he was reluctant to pay, as I suggest below.

16. And I note that one can find a different view of the matter in During (2008). 
barrier, which intervenes between our apprehension and the original meaning and import of reality. But it is forgotten that what is here called absolute reality, durée réelle, is itself no absolute but only signifies a standpoint of consciousness opposed to that of mathematics and physics. In the one case, we seek to gain a unitary and exact measure for all objective process, in the other we are concerned in retaining this process itself in its pure qualitative character, in its concrete fullness and subjective inwardness and "contentuality." The two standpoints can be understood in their meaning and necessity; neither suffices to include the actual whole of being in the idealistic sense of "being for us." The symbols that the mathematician and physicist take as a basis in their view of the outer and the psychologist in his view of the inner, must both be understood as symbols. Until this has come about the true philosophical view, the view of the whole, is not reached, but a partial experience is hypostasised into the whole (Cassirer 1923). ${ }^{17}$

A recurring theme in Canales's book is that the disagreement between Bergson and Einstein regarding time is one of the sources of the $20^{\text {th }}$ century rift between continental and analytic (or humanistic and science/ logic inspired) philosophical schools. I am not enough of a historian to have an informed opinion on this matter. ${ }^{18}$ But insofar as she is correct, then I suggest that that source of the rift was spurious. Bergson could have replaced his tortured denials of the clock paradox with a recognition that succession along time-like worldlines is dynamic and, at least potentially, lived. I contend that neither humanists nor scientists need dissent.

Čapek ends his chapter on Bergson and Einstein by noting that "it is clear that to separate what is living from what is dead in Bergson's interpretation of relativity theory is a complex task." My minimal hope is to convince the reader at least that Bergson's denial of the clock paradox is a dead element of his thought. My maximal hope is that reflection upon the clock paradox and STR will lead those who are sympathetic to Bergson's ideas to look more skeptically on his privileging one side of a deeply complex phenomenon (time only as psychological time) to a balanced appreciation of the whole (time as experienced by us and the same time as measured by clocks).

17. This quote appears on pages 454-455 of the Supplement to Cassirer's Substance and Function, "Einstein's Theory of Relativity considered from the Epistemological Standpoint," which first appeared in German in 1921. I quote from the English translation by William C. Swabey and Marie C. Swabey, which was first published by the Open Court Publishing Co. in 1923 and which was reprinted by Dover Publications in 1953. 18. For a different, but possibly complementary, account, see Friedman (2000). 


\section{Bibliography}

Arthur, Richard. 2019. The Reality of Time Flow. Cham: Springer.

Bergson, Henri. 1965. Duration and Simultaneity. Translated by Leon Jacobson. Indianapolis, New York, and Kansas City: The BobbsMerrill Company, Inc.

Canales, Jimena. 2015. The Physicist and the Philosopher. Princeton, NJ: Princeton University Press.

Čapek, Milič. 1971. Bergson and Modern Physics: A Reinterpretation and Re-evaluation. Dordrecht: Reidel.

Cassirer, Ernst. 1923. Einstein's Theory of Relativity considered from the Epistemological Standpoint. Chicago: The Open Court Publishing Co.

Chalmers, David. 2018. "Carnap's Second Aufbau and David Lewis's Aufbau." https://philarchive.org/archive/CHACSA-16v2. Accessed April 2019.

During, Elie. 2008. "Relativistic Time in Whitehead and Bergson." In Handbook of Whiteheadean Process Thought Volume 2, edited by Michel Weber, 259-281. Berlin: Ontos Verlag.

Friedman, Michael. 2000. A Parting of the Ways. Chicago: Open Court.

Geroch, Robert. 1978. General Relativity from A to B. Chicago: University of Chicago Press.

Hafele, J. C. and R. Keating. 1972a. "Around-the-World Atomic Clocks: Predicted Relativistic Time Gains.” Science (New Series) 177(4044): 166-168.

Hafele, J. C. and R. Keating. 1972b. "Around-the-World Atomic Clocks: Observed Relativistic Time Gains.” Science (New Series) 177(4044):168170.

Kügler, Peter. 2020. "What Bergson Should Have Said About Special Relativity." Synthese. https://link.springer.com/ article/10.1007\%2Fs11229-020-02716-x\#citeas. Accessed on May 28, 2020.

Marder, Leslie. 1971. Time and the Space Traveller. Philadelphia: University of Pennsylvlania Press.

Mermin, N. David. 1968. Space and Time in Special Relativity. Prospect Heights, Illinois: Waveland Press.

Popper, Karl. 1962. Conjectures and Refutations. New York and London: Basic Books. 
Rovelli, Carlo. 2019. "Neither Presentism nor Eternalism." Foundations of Physics 49: 1325-1335.

Savitt, Steven. 2009. “The Transient nows.” In Quantum Reality, Relativistic Causality, and Closing the Epistemic Circle, edited by Wayne Myrvold and Joy Christian, 349-362. Berlin, Heidelberg, Dordrecht, and New York City: Springer.

Savitt, Steven. 2020. "In Search of Passing Time." In Spacetime 19092019, edited by Reinoud Jan Slagter and Zoltan Keresztes, 87-100. Montreal: Minkowski Institute Press.

Steven Savitt is a professor emeritus at the University of British Columbia. His philosophical interests are in physics, metaphysics and meta-metaphysics. $\mathrm{He}$ has recently written primarily about the nature of time.

\begin{abstract}
In the famous 1922 debate with Einstein, Bergson was mistaken in his rejection of the so-called twin or clock "paradox." Consistent with at least one of his core beliefs (that time is succession) Bergson could have maintained that there is genuine time along each twin's worldline in a relativistic spacetime, since there is succession (of events) along every such world line. Had he taken such a stance, we might have been spared the confused idea that relativistic spacetimes are (or represent) static or "block" universes. Moreover, in a recent book on the debate Jimena Canales claims that the Einstein/ Bergson difference was one of the sources of the rift between continental and analytic (or at least science-oriented) philosophy. Insofar as her claim is true, my argument entails that the rift has a spurious origin. Recognition of this fact by contemporary Bergsonians might help to close or bridge it.
\end{abstract}

Keywords: Bergson, Einstein, temporal becoming, special relativity, twin paradox.

Résumé : Lors du célèbre débat de 1922 avec Einstein, Bergson s’est trompé en rejetant le "paradoxe" des jumeaux ou de l'horloge. En accord avec au moins une de ses croyances fondamentales (le temps est une succession), Bergson aurait pu soutenir qu'il existe un temps réel dans la ligne d'univers (worldline) de chaque jumeau dans un espace-temps relativiste, puisqu'il existe une succession (d'événements) dans chaque ligne d'univers. $S^{\prime}$ 'il avait adopté une telle position, on nous aurait épargné l'idée confuse que les espaces-temps relativistes sont (ou représentent) des univers statiques ou "en bloc." De plus, dans un livre récent sur le débat, Jimena Canales affirme que la controverse entre Einstein et Bergson a été l'une des sources du fossé entre la philosophie continentale et analytique (ou du moins la philosophie orientée vers la science). Dans la mesure où cette affirmation est vraie, mon argument implique que ce clivage a une origine fallacieuse. La reconnaissance de ce fait par les bergsoniens contemporains pourrait contribuer à le combler ou à le faire disparaître.

Mots-clés: Bergson, Einstein, devenir temporel, relativité restreinte, paradoxe des jumeaux. 
